\title{
Erratum to: Determinants of patient satisfaction and function related to vision following cataract surgery in eyes with no visually consequential ocular co-morbidity
}

\author{
Clare Kirwan $^{1,2,3}$ • John M. Nolan ${ }^{3} \cdot$ Jim Stack $^{3}$ - Tara C. B. Moore ${ }^{1}$. \\ Stephen Beatty ${ }^{2,3}$
}

Published online: 26 June 2015

(C) Springer-Verlag Berlin Heidelberg 2015

Erratum to: Graefes Arch Clin Exp Ophthalmol

DOI 10.1007/s00417-015-3038-7

Reason: Misleading message in "Conclusion" at the end of the abstract due to typographical mistake - i.e. " ...negatively associated with spectacle in dependence, dysphotopsia and function related to vision (NEI VF-11) score. " ("in" is not correct)

Corrected version: “.... and negatively associated with spectacle dependence, dysphotopsia and function related to vision (NEI VF-11) score."

The online version of the original article can be found at http://dx.doi.org/ 10.1007/s00417-015-3038-7.

Clare Kirwan

clare@ivr.ie

1 Biomedical Science Research Institute, University of Ulster,

Coleraine, Northern Ireland, UK

2 Institute of Eye Surgery and Institute of Vision Research, Whitfield

Clinic, Suite 14, Cork Road, Waterford, Ireland

3 Macular Pigment Research Group, Waterford Institute of

Technology, Waterford, Ireland 